\title{
Goldenhar syndrome presenting as limbal dermoid cyst: A case report
}

\author{
Sajid Ansari, Kanchan Dhungel, Kaleem Ahmad, Mukesh Kumar Gupta, \\ Md. Farid Amanullah, Pranav Kumar Santhalia, Raj Kumar Rauniyar
}

\begin{abstract}
Introduction: Goldenhar syndrome is a rare congenital disorder which manifests as ocular, auricular, dental and vertebral and several other systemic abnormalities. The abnormalities in the organs developing from first and second branchial arches during blastogenesis cause morphological anomalies in this disorder. Case Report: We report a case of Goldenhar syndrome in a 12-year-old Asian girl with limbal dermoid cyst, lateral canthal tag, preauricular appendage and malocclusion of teeth. Computed tomography scan and grayscale ultrasonography of orbit revealed dermoid cysts. Multidisciplinary treatment approach was advised; dermoid cyst was excised surgically and dental consultation was advised for malocclusion. Conclusion: This case has been
\end{abstract}

Sajid Ansari ${ }^{1}$, Kanchan Dhungel ${ }^{2}$, Kaleem Ahmad², Mukesh Kumar Gupta ${ }^{2}$, Md. Farid Amanullah ${ }^{3}$, Pranav Kumar Santhalia ${ }^{4}$, Raj Kumar Rauniyar ${ }^{5}$

Affiliations: ${ }^{1}$ Senior Resident, MD, Department of Radiodiagnosis and imaging, BP Koirala Institute of Health Sciences, Dharan, Nepal; ${ }^{2}$ Associate Professor, MD, Department of Radiodiagnosis and imaging, BP Koirala Institute of Health Sciences, Dharan, Nepal; ${ }^{3}$ Senior Resident, MS, Department of Orthopaedics, BP Koirala Institute of Health Sciences, Dharan, Nepal; 4Junior Resident, MD, Department of Radiodiagnosis and imaging, BP Koirala Institute of Health Sciences, Dharan, Nepal; ${ }^{5}$ Professor, MD, Department of Radiodiagnosis and imaging, BP Koirala Institute of Health Sciences, Dharan, Nepal.

Corresponding Author: Sajid Ansari, H-2733, BPKIHS, Dharan, Sunsari, Nepal; Postal Code: 56700; Ph: 009779722541028; E-mail: drsajidansari2012@gmail.com

Received: 27 December 2012

Accepted: 18 February 2013

Published: 01 July 2013 presented to increase the awareness about this rare entity, to highlight the importance of typical clinical and radiological findings and its association with various systemic conditions. Multidisciplinary treatment approach and longterm regular follow-up is important to monitor the growth and development of patients.

Keywords: Goldenhar syndrome, Dermoid cyst, Preauricular appendages, Malocelusion

$* * * * * * * * *$

Ansari S, Dhungel K, Ahmad K, Gupta MK, Amanullah MF, Santhalia PK, Rauniyar RK. Goldenhar syndrome presenting as limbal dermoid cyst: A case report with clinical and radiological findings. International Journal of Case Reports and Images 2013;4(7):384-387.

$* * * * * * * * *$

doi:10.5348/ijcri-2013-07-337-11

\section{INTRODUCTION}

Goldenhar syndrome is a rare congenital disorder with occurrence of about 1 per 5800 births and male:female ratio of 3:2. In 1952, Goldenhar was first to describe this rare disorder. It comprises various anomalies such as periauricular appendages, limbal dermoid and auricular malformations. Goldenhar syndrome is also known as oculo-auriculo-vertebral dysplasia and hemifacial microsomia [1]. The abnormalities in the organs developing from first and second branchial arches during blastogenesis cause morphological anomalies. It has a multifactorial etiopathology that includes nutritional and environmental factors [2]. 


\section{CASE REPORT}

A 12-year-old Asian girl presented to our department for computed tomography (CT) scan of orbits for evaluation of ocular dermoid cyst. The child was born to non-consanguineous parents with uneventful prenatal and antenatal period. There was no relevant family history. Her mental status was normal and there was no evidence of developmental delay. Left limbal dermoid cyst measuring $0.5 \times 0.5 \mathrm{~cm}$ with hair follicles was seen at 5 o'clock position since birth (Figure $1 \mathrm{~A}-\mathrm{B}$ ), which is painless and not increasing in size. A dermal tag was seen at the lateral canthus of the left upper eyelid (Figure 1A). There was no redness or discharge from the eyes and ocular motility was normal bilaterally. Her visual acuity was normal (6/6). An accessory preauricular tag was seen on the left side (Figure 1C). Audiological examination shows no evidence of hearing impairment. Intraoral examination revealed malocclusion of lower dentition (Figure 2).

Cardiovascular system and central nervous system were normal. Hematological investigation showed hemoglobin $11.9 \mathrm{~g} / \mathrm{dL}$, total leukocyte count (TLC) $8500 / \mu \mathrm{L}$, neutrophils 38\%, lymphocytes $48 \%$, eosinophils $15 \%$, monocytes $5 \%$ and platelet counts $274 \times 10^{3} / \mu \mathrm{L}$. Routine and microscopic urine investigation were within the normal limits. No abnormality was seen on plain radiograph (anteroposterior and lateral views) of cervical and thoracic spine.

The CT scan of orbits showed a hypodense lesion of fat attenuation measuring $0.8 \times 0.5 \mathrm{~cm}$ on the lateral aspect of the left orbit abutting the lateral margin of the globe, suggestive of dermoid cyst (Figure 3). Another small similar lesion measuring $0.5 \times 0.5 \mathrm{~cm}$ seen at the left limbal region (suggestive of dermoid cyst). Grayscale ultrasonography (USG) of left orbit showed a small echogenic lesion at the limbus (Figure 4). Clinical and radiological features were suggestive of Goldenhar syndrome. Pediatric consultation was also done to rule out any systemic associations. She was referred to dentist for needful correction of the maloccluded teeth.
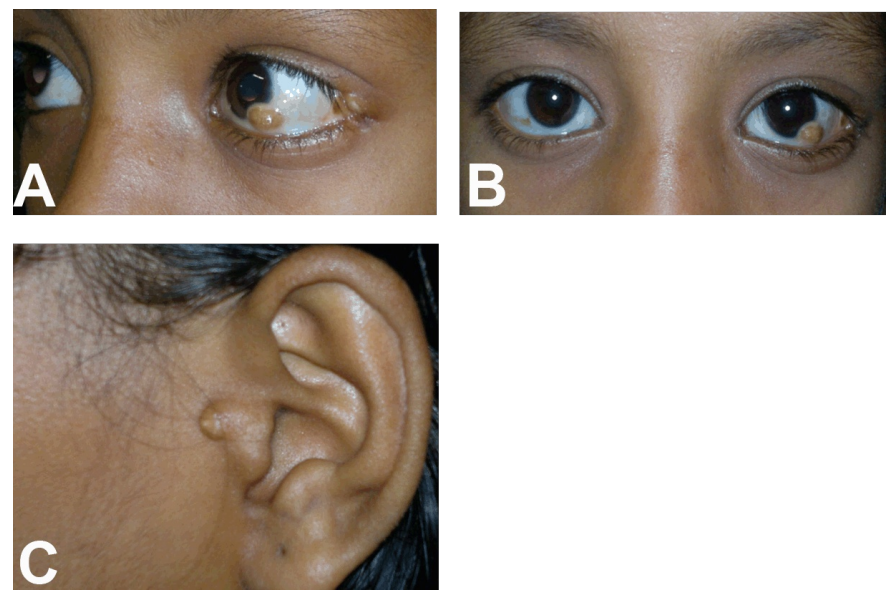

Figure 1: (A, B) The patient showing left limbal dermoid cyst, dermal tag at the lateral canthus of the left upper eyelid, (C) An accessory left preauricular tag.

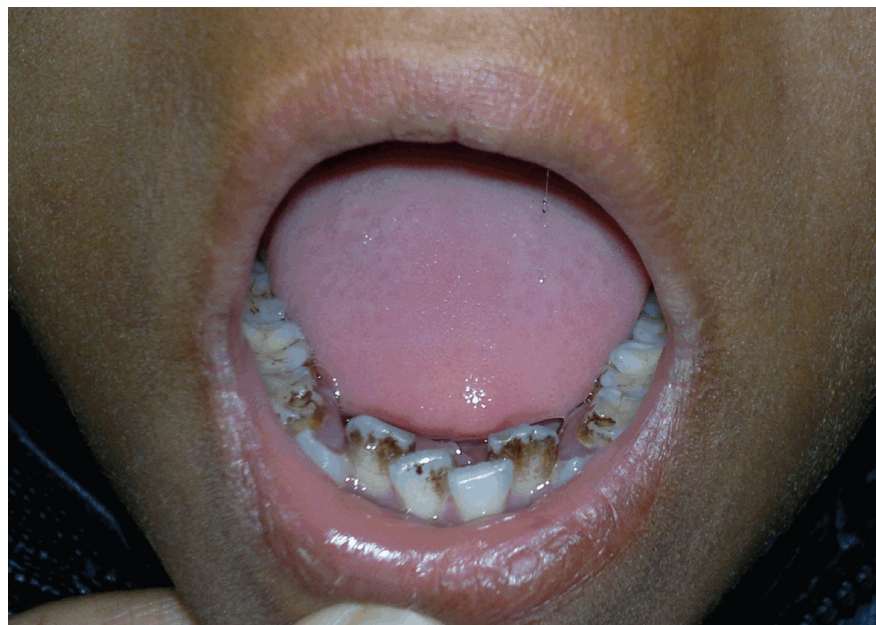

Figure 2: Intraoral examination revealing malocclusion of lower dentition.

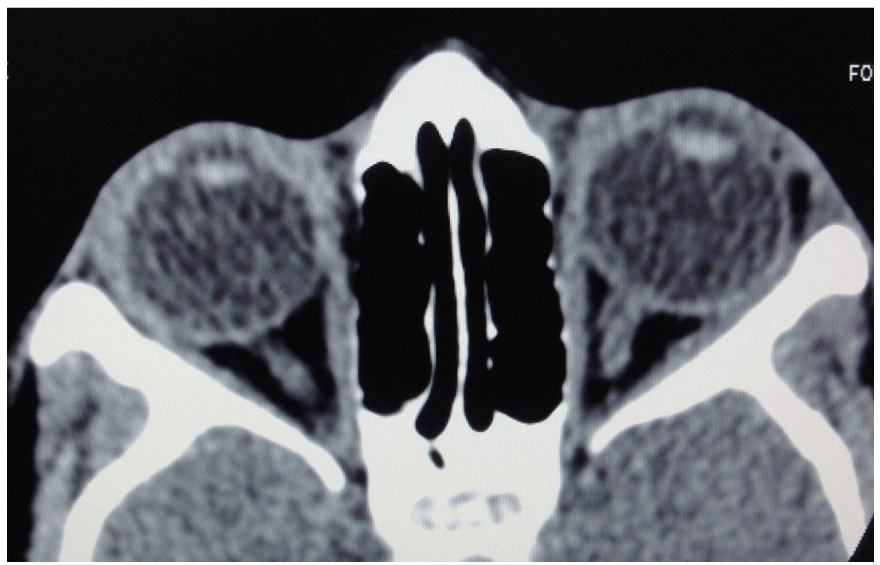

Figure 3: Contrast enhanced axial section computed tomographic image of orbit showing a hypodense lesion of fat attenuation on the lateral aspect of the left orbit abutting the lateral margin of the globe and another small similar lesion at the left limbal region (suggestive of dermoid cyst).

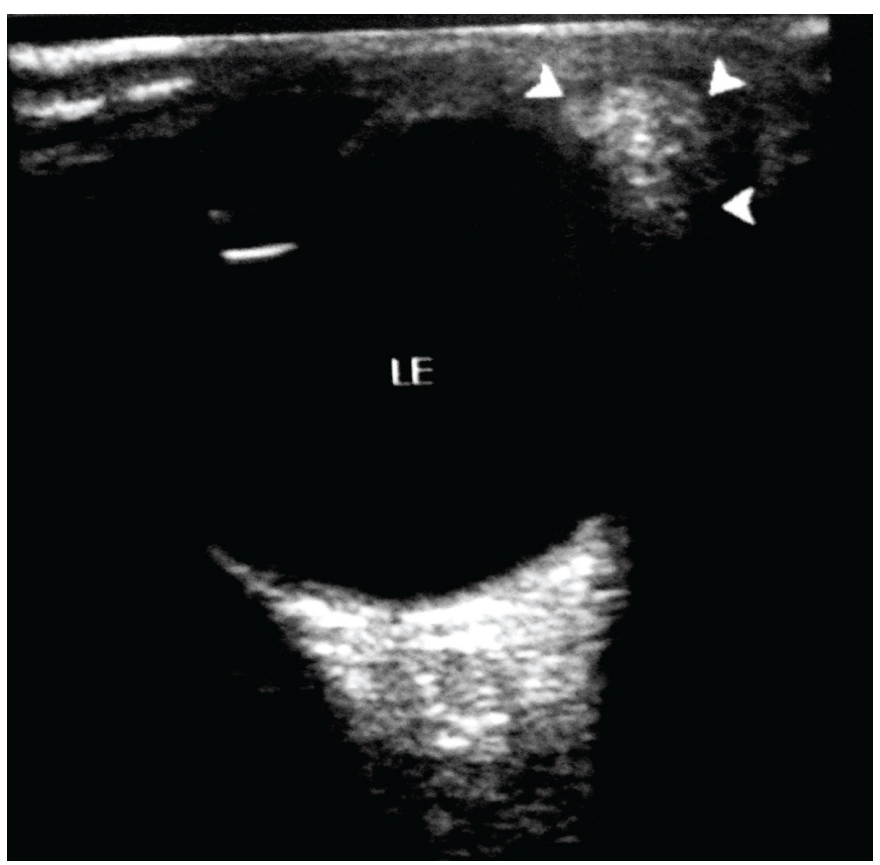

Figure 4: Grayscale ultrasonography of left orbit showed a small echogenic lesion (white arrow) at the limbus (suggestive of dermoid cyst). 
Surgical excision of the dermoid cysts was done. Postoperative period was uneventful.

\section{DISCUSSION}

Goldenhar syndrome has characteristic features of epibulbar dermoids, auricular abnormalities, preauricular appendages and fistulas, dacryocystitis, hypoplasia of the malar bones, mandible and zygomatic arch. It is also associated with macrostomia, micrognathia, cleft palate, bifid tongue and malocclusion, vertebral abnormalities, facial muscle hypoplasia, neurological, visceral, cardiac and genitourinary abnormalities [2-6].

In $40 \%$ cases significant hearing loss have been reported [3]. The presence of anomalies of the ear and of appendages on the ear is sufficient for the diagnosis. In our patient, preauricular appendage was seen but there was no hearing loss.

Epibulbar dermoid is found in $30-60 \%$ cases with ocular manifestation of Goldenhar syndrome [7]. Dermoid cysts are usually observed on the inferotemporal or superotemporal aspect of the limbus. Astigmatism is a rare manifestation of the disease due to the corneal and scleral invasion by the lesions. In our patient, the dermoid was seen on the inferotemporal aspect of the limbus. In this disorder, the delayed development of teeth can be seen rarely; malocclusion was observed in our patient.

Malformations are usually bilateral in about $10-33 \%$ of cases, with one side of the body affected more leading to asymmetry. In most of the cases, right sided involvement is more severely affected than the left [8]. Cardiovascular abnormalities are observed in range of $5-58 \%$ of cases. However, there were no cardiovascular abnormalities in our patient. Sporadic autosomal dominant and autosomal recessive modes of inheritance have been seen in most of the cases along with association of Trisomy of 7 and 22 [9]. Goldenhar syndrome has also been found in children born to pregnant women who were exposed to various teratogenic agents like retinoic acid, primidone and thalidomide [10]. In our case there was no history of maternal drug intake, any febrile illness or diabetes during pregnancy.

Prognosis of this disease is good in otherwise uncomplicated cases without any systemic associations. Multidisciplinary treatment approach is required which varies with age and systemic associations. Ocular dermoid cysts can be excised surgically. The ophthalmologist should focus on visual consequences, early treatment and meticulous follow-up of the patients. Reconstructive oral and facial surgeries are required for malocclusion and bony deformities.

\section{CONCLUSION}

This case has been presented to increase the awareness about this rare entity, to highlight the importance of typical clinical and radiological findings and its association with various systemic conditions. Multidisciplinary treatment approach and long-term meticulous follow-up is important to monitor the growth and the development of patients.

$* * * * * * * * *$

\section{Author Contributions}

Sajid Ansari - Substantial contributions to conception and design, Acquisition of data, Analysis and interpretation of data, Drafting the article, Final approval of the version to be published

Kanchan Dhungel - Substantial contributions to conception and design, Acquisition of data, Drafting the article, Revising it critically for important intellectual content, Final approval of the version to be published

Kaleem Ahmad - Analysis and interpretation of data, Revising it critically for important intellectual content, Final approval of the version to be published

Mukesh Kumar Gupta - Substantial contributions to conception and design, Revising it critically for important intellectual content, Final approval of the version to be published

Md. Farid Amanullah - Substantial contributions to conception and design, Drafting the article, Revising it critically for important intellectual content, Final approval of the version to be published

Pranav Kumar Santhalia - Substantial contributions to conception and design, Acquisition of data, Analysis and interpretation of data, Revising it critically for important intellectual content

Raj Kumar Rauniyar - Substantial contributions to conception and design, Acquisition of data, Analysis and interpretation of data, Final approval of the version to be published

\section{Guarantor}

The corresponding author is the guarantor of submission.

\section{Conflict of Interest}

Authors declare no conflict of interest.

\section{Copyright}

(C) Sajid Ansari et al. 2013; This article is distributed under the terms of Creative Commons attribution 3.0 License which permits unrestricted use, distribution and reproduction in any means provided the original authors and original publisher are properly credited. (Please see www.ijcasereportsandimages.com /copyright-policy.php for more information.)

\section{REFERENCES}

1. Altamar-Ríos J. [Goldenhar's syndrome: a case report]. An Otorrinolaringol Ibero Am 1998;25(5):491-7.

2. Reddy P. Facio-auricular vertebral syndrome- a case report. Indian Journal of Human Genetics 2005;13:156-8. 
3. Pinheiro AL, Araujo LC, Oliveira SP, Sampaio MC, Freitas AC. Goldenhar's syndrome--case report. Braz Dent J 2003;14(1):67-70.

4. Ignacio Rodríguez J, Palacios J, Lapunzina P. Severe axial anomalies in the oculo-auriclo-vertebral (Goldenhar) complex. Am J Med Genet 1993;47(1):69-74.

5. Lessick M, Vasa R, Israel J. Severe manifestations of oculo auriculo vertebral spectrum in a cocaineexposed infant. J Med Genet 1991;28(11):803-4.

6. Morrison PJ, Mulholland HC, Craig BG, Nevin NC. Cardiovascular abnormalities in the oculo-auriculovertebral spectrum (Goldenhar Syndrome). Am J Med Genet 1992;44(4):425-8.
7. Mehta B, Nayak C, Savant S, Amladi S. Goldenhar syndrome with unusual features. Indian J Dermatol Venereol Leprol 2008;74(3):254-6.

8. Rao VA, Rao S. Lamba PA. Goldenhar's syndrome (an analysis of 10 cases and aetiological considerations). Indian $\mathrm{J} \quad$ Ophthalmol 1982;30(3):147-9.

9. Sujit Kumar GS, Haran RP, Rajshekhar V. Delleman syndrome with Goldenhar overlap. J Pediatr Neurosci 2009 Jan;4(1):53-5.

10. Kapur R, Kapur R, Sheikh S, Jindal S, Kulkarni S. Hemifacial microsomia: A case report. J Indian Soc Pedod Prevent Dent 2008;26:34-40.
Access full text article on other devices

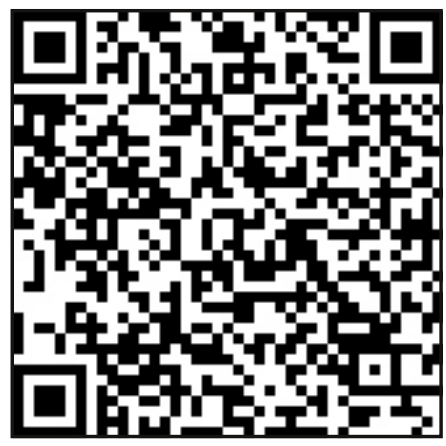

Access PDF of article on other devices

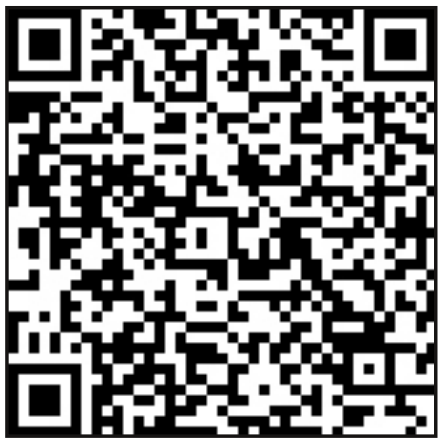

